\title{
Core Radial Electric Field and Transport in Wendelstein 7-X Plasmas
}

N.A. Pablant, ${ }^{1}$ A. Langenberg, ${ }^{2}$ A. Alonso, ${ }^{3}$ C.D. Beidler, ${ }^{2}$ M. Bitter, ${ }^{1}$ S. Bozhenkov, ${ }^{2}$ R. Burhenn, ${ }^{2}$ M. Beurskens, ${ }^{2}$ L. Delgado-Aparicio, ${ }^{1}$ A. Dinklage, ${ }^{2}$ G. Fuchert, $^{2}$ D. Gates, ${ }^{1}$ J. Geiger, ${ }^{2}$ K.W. Hill, ${ }^{1}$ U. Hoefel, ${ }^{2}$ M. Hirsch, ${ }^{2}$ J. Knauer, ${ }^{2}$ A. Krämer-Flecken, ${ }^{4}$ M. Landreman, ${ }^{5}$ S. Lazerson, ${ }^{1}$ H. Maassberg, ${ }^{2}$ O. Marchuk, ${ }^{4}$ S. Massidda, ${ }^{6}$ G.H. Neilson, ${ }^{1}$ E. Pasch, ${ }^{2}$ S. Satake, ${ }^{7,8}$ J. Svennson, ${ }^{2}$ P. Traverso, ${ }^{6}$ Y. Turkin, ${ }^{2}$ P. Valson, ${ }^{2}$ J.L. Velasco, ${ }^{3}$ G. Weir, ${ }^{2}$ T. Windisch, ${ }^{2}$ R.C. Wolf, ${ }^{2}$ M. Yokoyama, ${ }^{7,8}$ D. Zhang, ${ }^{2}$ and the W7-X Team

1) Princeton Plasma Physics Laboratory

2) Max-Planck-Institut für Plasmaphysik

3) Laboratorio Nacional de Fusion, CIEMAT

${ }^{4)}$ Forschungszentrum Jülich

5) University of Maryland

6) Auburn University

7) National Institute for Fusion Science

8) SOKENDAI (The Graduate University for Advanced Studies)

(Dated: 28 December 2017) 


\section{ABSTRACT}

Results from the investigation of neoclassical core transport and the role of the radial electric field profile $\left(E_{r}\right)$ in the first operational phase of the Wendelstein 7-X (W7-X) stellarator are presented. In stellarator plasmas, the details of the $E_{r}$ profile are expected to have a strong effect on both the particle and heat fluxes. Investigation of the radial electric field is important in understanding neoclassical transport and in validation of neoclassical calculations.

The radial electric field is closely related to the perpendicular plasma flow $\left(u_{\perp}\right)$ through the force balance equation. This allows the radial electric field to be inferred from measurements of the perpendicular flow velocity, which can be measured using the x-ray imaging crystal spectrometer (XICS) and correlation reflectometry diagnostics. Large changes in the perpendicular rotation, on the order of $\Delta u_{\perp} \sim 5 \mathrm{~km} / \mathrm{s}$ $\left(\Delta E_{r} \sim 12 \mathrm{kV} / \mathrm{m}\right)$, have been observed within a set of experiments where the heating power was stepped down from $2 M W$ to $0.6 M W$. These experiments are examined in detail to explore the relationship between heating power, temperature and density profiles and the radial electric field.

Finally the inferred $E_{r}$ profiles are compared to initial neoclassical calculations using measured plasma profiles. The results from several neoclassical codes, sf InCS, FORTEC-3D and DKES, are compared both with each other and the measurements. These comparisons show good agreement, giving confidence in the applicability of the neoclassical calculations to the W7-X configuration. 


\section{INTRODUCTION}

Perpendicular plasma flow profiles from the first operational phase of the Wendelstein 7-X stellarator (W7-X) have been measured through the use of x-ray spectroscopy. These perpendicular plasma flow profiles are closely related to the radial electric field $\left(E_{r}\right)$ through the force balance equation. In stellarator plasmas the neoclassical particle fluxes are not intrinsically ambipolar, which leads to the formation of a radial electric field that enforces ambipolarity. Local neoclassical theory can predict the $E_{r}$ profile, which is strongly tied to both the particle and heat fluxes as well as the bootstrap current ${ }^{1}$. Initial measurements of the perpendicular plasma flow $\left(u_{\perp}\right)$ and the inferred $E_{r}$ profiles in W7-X are presented and compared with predictions from neoclassical theory.

Wendelstein $7-\mathrm{X}$ is the first large scale, optimized stellarator ${ }^{2,3}$. One of the important optimization targets in the W7-X design was the reduction of the neoclassical transport through shaping of the magnetic equilibrium ${ }^{4}$. The optimization of neoclassical transport was achieved by a reduction of the radial drift velocities whose properties are captured in the value of the effective helical ripple $\epsilon_{e f f}{ }^{3}$. The impact on confinement has been investigated in 1D transport simulations (See Ref. 5) using the neoclassical transport coefficients from the Drift-Kinetic Equation Solver DKES $\left.{ }^{6}\right)$.

In addition to evaluating the overall success of the optimization, it is important to examine the accuracy of the neoclassical codes and the validity of any simplifying assumptions that are used in an optimized stellarator design. Neoclassical optimization will continue to play a central role in the design of future stellarator reactors, making validation a critical topic in stellarator research.

\section{DIAGNOSTIC METHOD}

Measurements of the plasma flow are made using the x-ray imaging crystal spectrometer $(\mathrm{XICS})^{7}$. The XICS diagnostic relies on spectral emission from highly charged argon ions seeded into the plasma in trace amounts. During the first W7-X experimental campaign this diagnostic was configured to measure the emission from the $A r^{16+}$ charge state (He-like argon).

The raw measurements from the XICS system provide a one dimensional wavelength 
resolved image of line integrated emission. Using standard Doppler spectroscopy techniques, this diagnostic can provide line-integrated profiles of the ion-temperature $\left(T_{i}\right)$ from line broadening, electron temperature $\left(T_{e}\right)$ from line ratios, perpendicular flow velocity $\left(u_{\perp}\right)$ from line shifts and impurity concentration from the line brightness. Tomographic inversion, using a known plasma equilibrium is used to infer the local plasma parameters from the line integrated data ${ }^{8,9}$. A description of the XICS system on W7-X can be found in Ref. 7 and the diagnostic concept has been explained in detail by Bitter et al. in Ref. 10.

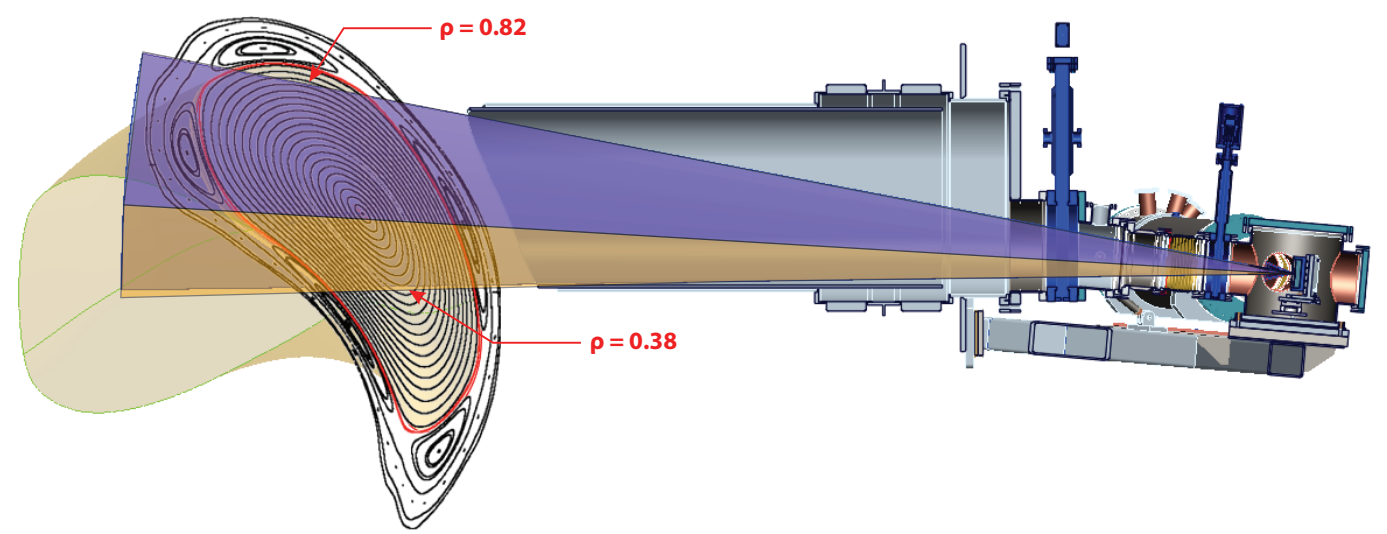

FIG. 1. Viewing geometry of the XICS diagnostic on W7-X.

The line integrated flow velocity profiles are found from the Doppler shift of the spectral lines. The XICS viewing geometry, as seen in Fig.1, is primarily sensitive to the component of the velocity that is perpendicular to the magnetic field lines. The flow velocity in a stellarator is not expected to be constant on a flux surface, and this variation must be accounted for as part of the tomographic inversion. A simple form for the variation of the perpendicular flow on a flux surface can be found using the radial force balance equation given the assumption that the plasma potential and plasma pressure are flux surface functions.

With these assumptions the local perpendicular flow, $\boldsymbol{u}_{\perp}$, can be related to the flux surface average flow, $U_{\perp}$, by the following expression:

$$
\boldsymbol{u}_{\perp}=\boldsymbol{f} U_{\perp}, \quad \boldsymbol{f}=-\frac{\langle B\rangle}{\langle|\nabla \rho|\rangle}\left(\frac{\boldsymbol{B} \times \nabla \rho}{B^{2}}\right)
$$

Where $\rho=\sqrt{\psi / \psi_{\text {edge }}}$ is a normalized radial flux coordinate, $\psi$ is the toroidal flux enclosed in a flux surface, $\langle\cdot\rangle$ denotes a flux surface average, and the perpendicular direction on a flux surface is defined by $\nabla \rho \times \boldsymbol{B}$. Additional details on the derivation of this expression 
are given in Ref. 11. This expression for the variation of the perpendicular flow on a flux surface is used during tomographic inversion in order to find $U_{\perp}$ from the line integrated flow measurements.

The viewing chords in the W7-X system are nearly perpendicular to the magnetic axis, and are therefore nearly insensitive to the parallel flow. In addition, the parallel flow is expected to be heavily damped due to neoclassical viscosity. For these reasons the parallel velocity is neglected in the current work.

To derive the radial electric field from the flux surface averaged perpendicular flow velocity $\left(U_{\perp}\right)$ the radial force balance equation can be used.

$$
\left\langle E_{r}\right\rangle=\frac{1}{e n_{I} Z_{I}} \frac{\partial p_{I}}{\partial \rho}\langle|\nabla \rho|\rangle-\left\langle u_{\perp} B\right\rangle
$$

Where $p_{I}, n_{I}$ and $Z_{I}$ denote the pressure, density and charge of the ion species being measured. The pressure gradient term is small for the flat ion pressure profiles seen at W7$\mathrm{X}$, and particularly for $A r^{16+}$ where this term is weighted by $1 / Z_{I}=1 / 16$, and has been neglected in the results shown in this work.

In order to infer the radial electric field using this procedure, only the flow of one particular impurity charge state is required, in this case $\mathrm{Ar}^{16+}$. While the rotation of the bulk ions can be expeceted to differ from argon ions due to different weighting of the pressure gradient term, this difference does not affect the measurement of $E_{r}$.

The tomographic inversions utilized a vacuum VMEC equilibrium, based on the measured coil currents for the particular scenario; the use of the vacuum solution is justified because of the small beta value for these discharges. The value of the volume averaged beta $(\langle\beta\rangle)$ at maximum power was approximately $0.3 \%$, while the value of beta on axis $\left(\beta_{0}\right)$ was approximately $2 \%^{12}$. The plasma edge is defined by the location of the plasma limiter structures.

The achievable spatial and temporal resolution of the XICS measurements is limited by the intensity of the argon emission, and is therefore dependent on the amount of injected argon and the plasma conditions. For typical W7-X discharges the amount of argon seeded into the plasma is less than $n_{A r} / n_{e}<10^{-4}$. This level of argon seeding has been found to be non-perturbative to the plasma through a series of experiments in which different amounts of argon were injected into a steady state plasma, and the effect on the plasma profiles 
observed. With this level of argon seeding flow velocity measurements can be made with temporal and spatial resolutions of $10 \mathrm{~ms}$ and $2 \mathrm{~cm}$ respectively and an accuracy of $\approx 1 \mathrm{~km} / \mathrm{s}$, which corresponds to a line shift of $0.01 \mathrm{~m} \AA$ (0.025 pixels), and ultimately to accuracy in $E_{r}$ of $\approx 2.5 \mathrm{kV} / \mathrm{m}$. The accuracy of the velocity measurements can be improved substantially by increasing the integration time through software binning of multiple frames.

Measurements of the perpendicular plasma flow are also available on W7-X through the use of the correlation reflectometry diagnostic. This system is able to measure the flow velocity of density fluctuations through temporal correlation of fluctuations and poloidally separated measurement locations. Radial profiles are possible by sweeping the probing frequency over time, and therefore changing the density at which reflection occurs. In the first operational phase of W7-X, denoted as OP1.1, the radial range of the correlation reflectometry diagnostic was generally limited to the outer half of the plasma radius. More details on this diagnostic can be found in Ref. 13-15.

\section{CORE ELECTRON ROOT CONFINEMENT (CERC)}

During the first W7-X campaign hydrogen and helium plasmas were produced using up to $4 \mathrm{MW}$ of centrally deposited electron cyclotron radiofrequency heating (ECRH). Typical plasmas had central electron temperatures of 5-7 keV, central ion temperatures of 1.5-2.2 $\mathrm{keV}$ and central densities in the range of $2-4 \times 10^{19} \mathrm{~m}^{-3}$ (see Ref. 16). In previous stellarator experiments this set of conditions, with centrally peaked electron temperature profiles and $T_{e} \gg T_{i}$, is associated with the development of a positive radial electric field and a region of reduced heat transport in the plasma core ${ }^{17}$. These conditions, described as core electron root confinement (CERC), have been observed on W7-X as reported in Ref. 18.

In general, stellarator neoclassical particle fluxes may lead to multiple ambipolar solutions for $E_{r}$ in which the electron and ion fluxes become equal. For geometries similar to W7-X the ambipolarity requirement can lead to the existence of three solutions: the electron-root (typically resulting in a positive radial electric field), the ion-root (typically a negative radial electric field), and the unstable-root (typically a small positive solution). For a given radial location, and depending on the plasma profiles, only one of the electron or ion root solutions

may exist, or all three solutions may exist simultaneously. A detailed discussion of the neoclassical ambipolar $E_{r}$ solutions can be found in Ref. 17. 
The conditions of a positive core radial electric field are particularly well suited for validation of neoclassical calculations against experimental measurements, and also for examination of the validity of the assumptions and simplifications used in various neoclassical codes. Some of the specific assumptions used in neoclassical calculations, such as the handling of magnetic drifts and finite orbit effects, have the largest effect near the $E_{r}=0$ crossover. Other assumptions, such as the use of an incompressible $E \times B$ approximation in DKES, are expected to have a negligible contribution around $E_{r}=0$ and instead have the largest impact at large values of $E_{r}$. Experimental examination of plasmas with an $E_{r}$ crossover therefore provide important benchmark cases.

A plasma program was developed for the W7-X OP1.1 campaign to examine the effect of the input power on the radial electric field ${ }^{19}$. The program consists of three distinct steps of injected ECRH power $(2.0 \mathrm{MW}, 0.6 \mathrm{MW}$ and $1.3 \mathrm{MW})$ in a plasma with a nearly constant central density. The time history of this discharge can be seen in Fig.2, and temperature and density profiles at the three different power steps are shown in Fig.3. Additional details on these CERC discharges can be found in Ref. 19.

The $E_{r}$ profiles in Fig.4, which are inferred from the XICS measurements, show that all power phases of the program have an electron-root solution in the core of the plasma. However, the magnitude and radial extent of the core positive $E_{r}$ changes between the high and low power phases; the postive $E_{r}$ region shrinks by about $30 \%$ in minor radius when the power is reduced, with a corresponding decrease in magnitude.

The evolution of $E_{r}$ can be seen by looking at the change over time of the line integrated velocity measurements. In Fig.2 the line integrated velocity of each XICS sightline is shown relative to its value in the low power phase. As soon as the injected power is stepped up or down, both the flow velocity and the electron temperature begin to change. Within the time resolution of the XICS measurements used for this analysis, $30 \mathrm{~ms}$, the electron temperature and velocity appear to change simultaneously, which is consistent with the neoclassical understanding of $E_{r}$. The time for equilibration, both for the flow velocity and the electron temperature is approximately $100 \mathrm{~ms}$. This value is consistent with measurements of the global confinment time found from the total stored energy and input power and reported previously in ${ }^{12,20}$. 
W7-X Program 20160309.010
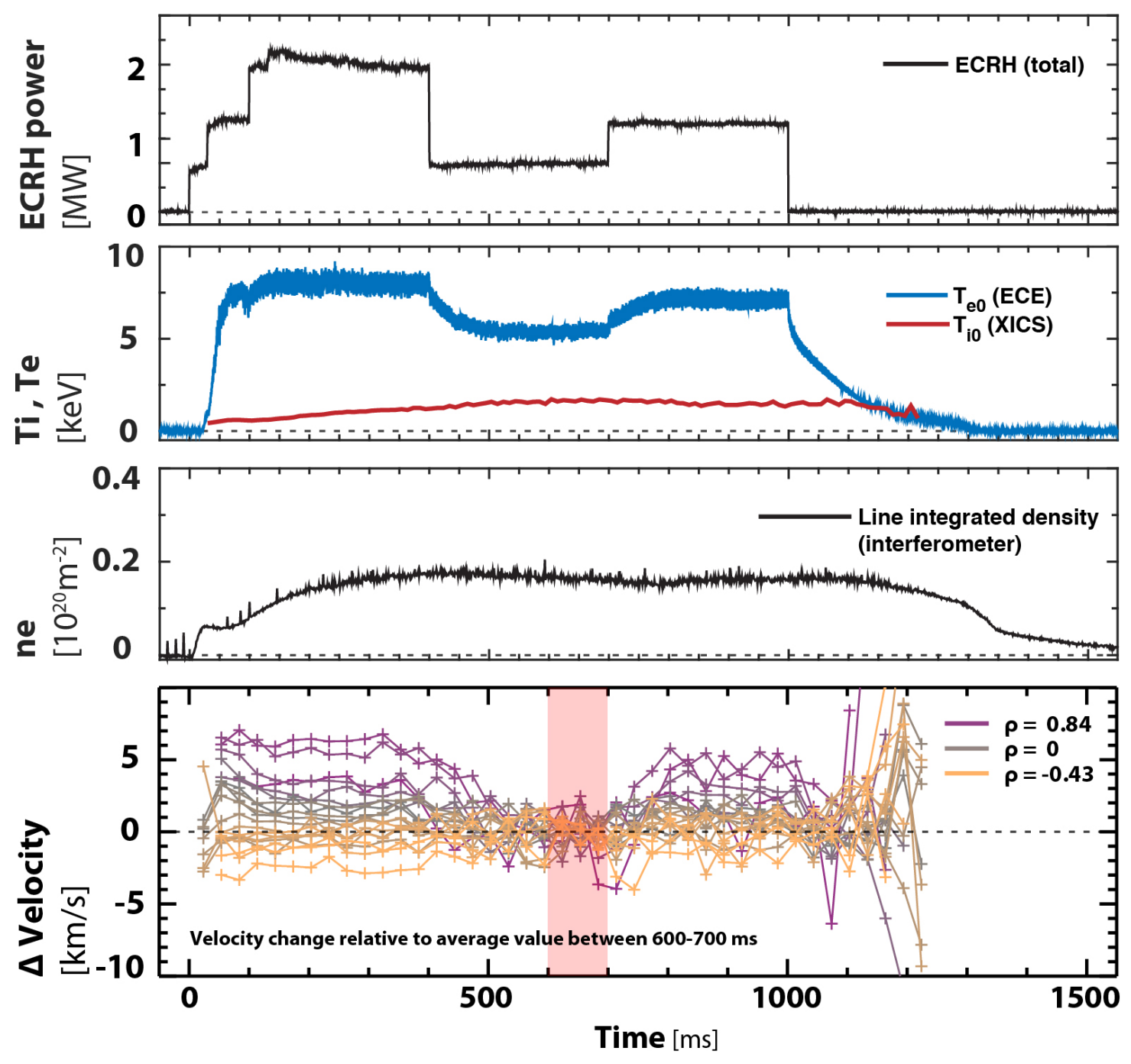

FIG. 2. Time history of the heating power, temperature and density of program 20160309.010 along with the dynamic evolution of the line integrated plasma flow as measured by XICS. Purple and yellow lines represent views above and below the magnetic axis respectively (see Fig.1). For clarity, the change in line integrated velocity seen in individual XICS sightlines is shown relative to the value averaged between 600-700 ms. While this plotting choice is primarily cosmetic, it captures the overall trend of the core rotation becoming smaller with reduced input power (see profile in Fig.3). The sightline labels correspond to the minimum flux surfurace that the outermost sightlines pass though (equivilent to the tangential surface).

\section{COMPARSION TO NEOCLASSICAL CALCULATIONS}

Several neoclassical codes are available that can calculate the radial electric field based on measured plasma profiles through the enforcement of ambipolarity of the particle fluxes. Three of these codes, DKES ${ }^{5,6}$, SFINCS ${ }^{21}$, and FORTEC-3D ${ }^{22,23}$, have been run for the program shown in Fig.2. Each of these codes take different approaches and make different assumptions 

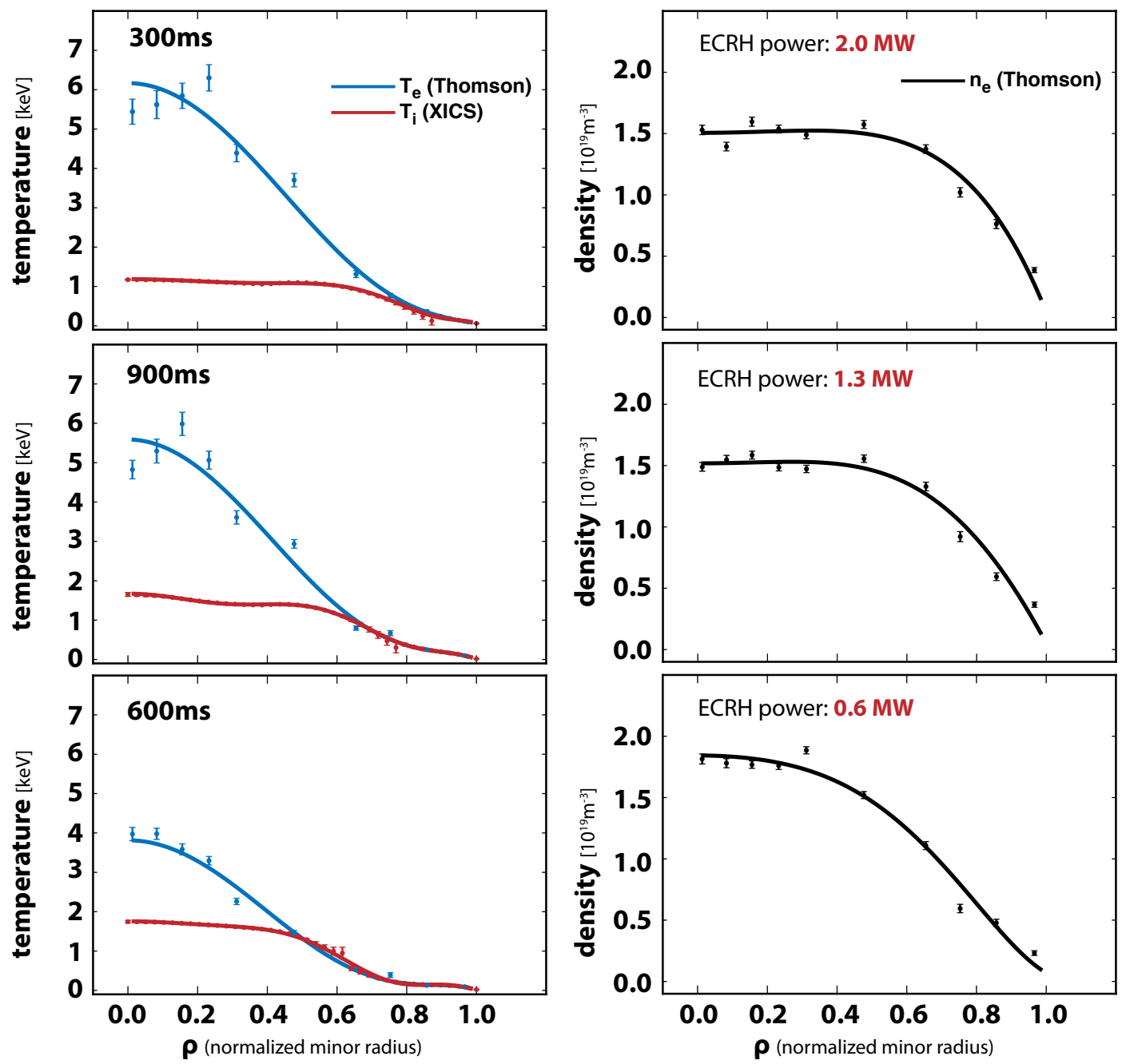

FIG. 3. Temperature and density profiles for the three powersteps in program 20160309.010. Electron temperature and density profiles are taken from Thomson scattering. Ion temperature profiles are taken from XICS. In the outermost portion of the profile, where ion temperature measurements were not available, Ti was set equal to Te. Profiles were fit using even polynomial functions in rho. These fitted profiles were used as inputs to the neoclasscical calculations.

while solving the drift kinetic equations. DKEs solves the 3D linearized drift-kinetic FokkerPlanck equations utilizing a pitch-angle scattering operator and neglecting the effect of magnetic drifts. SFINCS solves a set of local 4D drift-kinetic equations with the full linearized Folker-Planck operator and includes the effects of compressible $E \times B$ drift and momentum conservation. Finally FORTEC-3D utilizes a 5D Monte-Carlo solution and includes radial coupling and non-local effects due to the finite radial drift motions. A thorough discussion on the differences between these models and their assumptions can be found in Ref. 21 . 


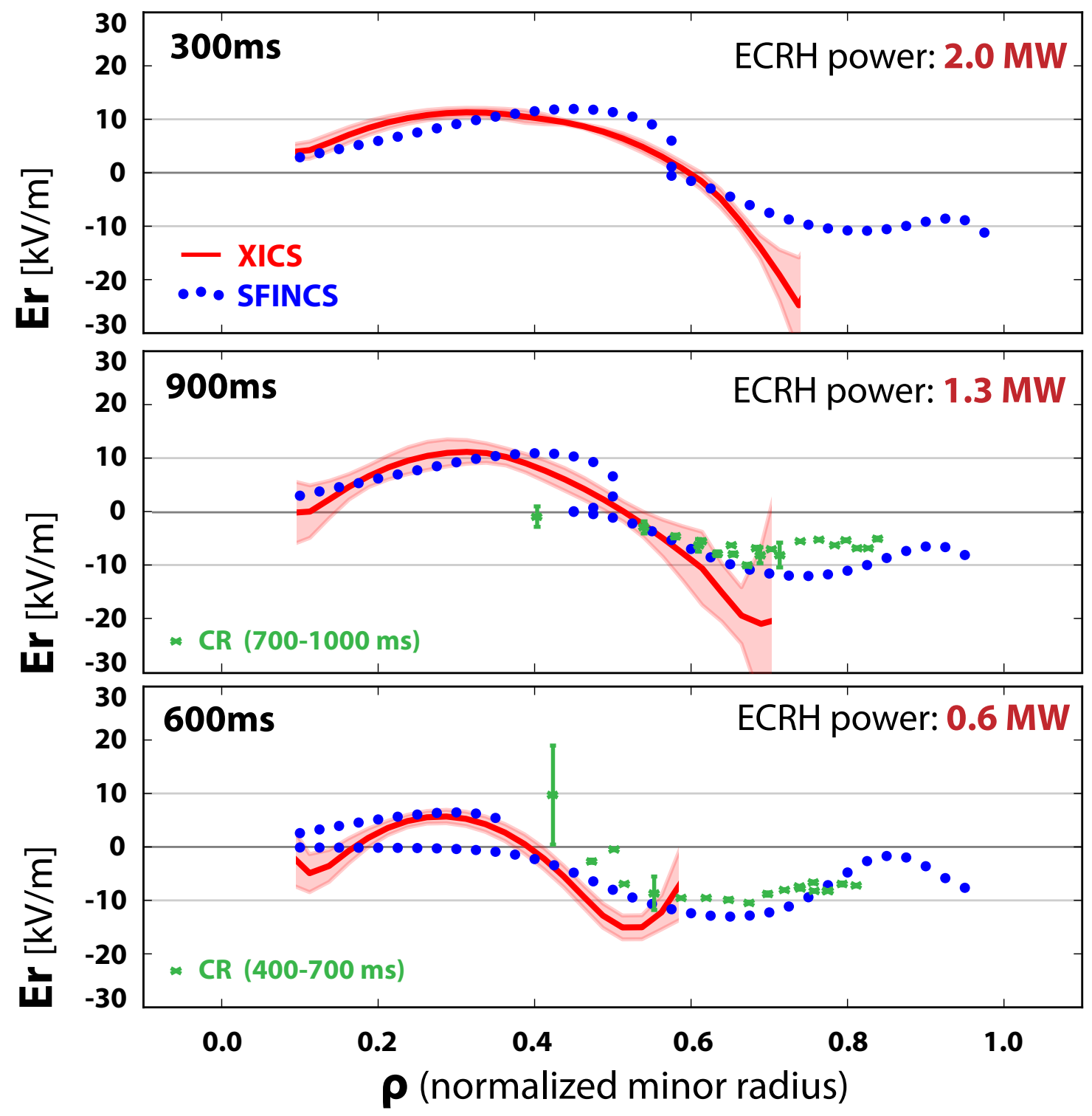

FIG. 4. Radial electric field profiles for program 20160309.010. Profiles inferred from XICS flow velocity measurements are shown in red. Predicted neoclassical $E_{r}$ profiles as calculated using SFINCS are shown in blue dots. Also shown are measurements of $E_{r}$ from the correlation reflectometer from two frequency scans during the discharge. In all cases $E_{r}$ refers to the flux surface average value of radial electric field as described in Section II.

In order to compare the neoclassical calculations with experiment, all three of these codes were run using the measured electron temperature $\left(T_{e}\right)$ and density $\left(n_{e}\right)$ profiles from Thomson scattering ${ }^{24}$, ion temperature $\left(T_{i}\right)$ profiles from XICS, and an assumption of a pure hydrogen plasma with $Z_{\text {eff }}=1$ (see Ref. 19). The same vMEC vacuum equilibrium solution used in the tomographic inversion was used in the neoclassical calculations.

A comparison of the $E_{r}$ profiles from XICS and SFincs is shown in Fig.4. Good agree- 
ment is seen, both in the magnitude and general shape of the $E_{r}$ profile and in the radial location of the crossover from electron-root to ion-root. Measurements from the correlation reflectometer (CR) also show good agreement with the neoclassical predictions in the outer half of the plasma (as shown in Fig.4), and are consistent with the location of the $E_{r}$ crossover from XICS and SFInCS. Details about the correlation reflectometer measurements are given in Ref. 13, along with an additional comparision between $E_{r}$ and neoclassical calculations for another similar W7-X program.

While the sensitivity of the XICS system is very poor in the outer part of the plasma due to low signal levels, a systematic difference between the XICS measurements and the neoclassical predictions can be seen. Several possible explanations for this difference are

possible: 1.) The contribution of the parallel flow to the XICS measurements. 2.) The contribution of the pressure gradient term to $E_{r}$. 3.) The assumption of Zeff=1 in the neoclassical calculations. 4.) Uncertainty in the measured profiles used for the calculations. These effects will be addressed in detail in a future publication.

Predictions from the three neoclassical codes, DKES, SFINCS and FORTEC-3D, are very similar and generally in excellent agreement. A comparison of the calculated ambipolar $E_{r}$ profiles from these codes is shown in Fig.5. The only noticeable difference between the codes is near the $E_{r}=0$ crossover, where FORTEC-3D shows a smooth transition between the ion and electron root solutions. This difference is expected as this region is where the non-local effects due to strong $E_{r}$-shear and the radial drift motions of ions are expected to be the most pronounced. The good agreement between the codes suggests that the approximations used by DKES and SFINCS are valid for these W7-X plasmas.

\section{NEOCLASSICAL HEAT TRANSPORT}

With the validation of the radial electric field profiles predicted by the neoclassical calculations it is possible to begin to investigate the neoclassical heat flux. Calculations of the ion and electron heat flux at the three different power steps are shown in Fig.6. Due the weak coupling between the ions and electrons at these densities, the majority of the heat is transported through the electron channel as expected. We additionally find that while the peak electron heat flux scales almost linearly with input power, the peak ion heat flux remains essentially constant. 


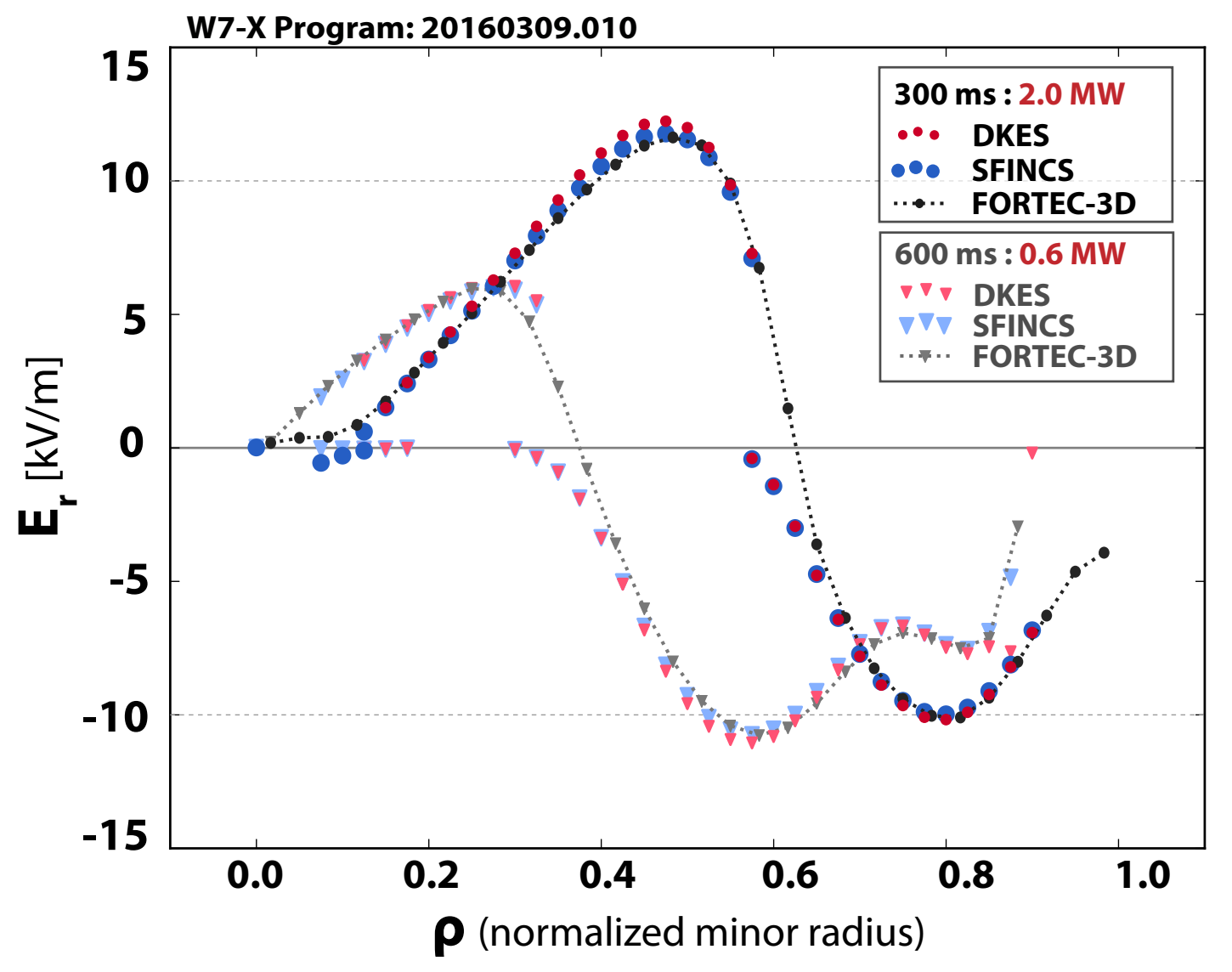

FIG. 5. Comparison of the ambipolar electric field predicted by three different neoclassical codes: DKES, SFINCS and FORTEC-3D. Caculations use the measured Te, Ti and Ne profiles from program 20160309.010 at $300 \mathrm{~ms}$ and $600 \mathrm{~ms}$ as shown in Fig.3. For the SFINCS and DKES results only the electron-root and ion-root solutions are shown; unstable-root solutions have been removed for clarity.

In order to compare the neoclassical heat flux to the input power, the total heat flux through a given flux surface is plotted in Fig.7. Because all of the input power is centrally deposited, this comparison provides a measure of how much of the total energy loss can be attributed to the neoclassical heat flux at each radial surface. In trying to understand the effect of neoclassical transport on the global confinement, an interesting quantity to consider is the maximum value of this heat flux. This quantity provides a measure of how much of the total power deposited in the core is lost to purely neoclassical processes.

In the core the peak neoclassical heat flux only accounts for roughly $70 \%$ of the input power. Specifically for the three power steps: $0.6 \mathrm{MW}, 1.3 \mathrm{MW}, 2.0 \mathrm{MW}$ the maximum calculated neoclassical flux is $0.4 \mathrm{MW}, 0.9 \mathrm{MW}$ and $1.4 \mathrm{MW}$ respectively, which leads to $67 \%, 69 \%$ and $72 \%$ of the core transport being attributable to the neoclassical transport. 

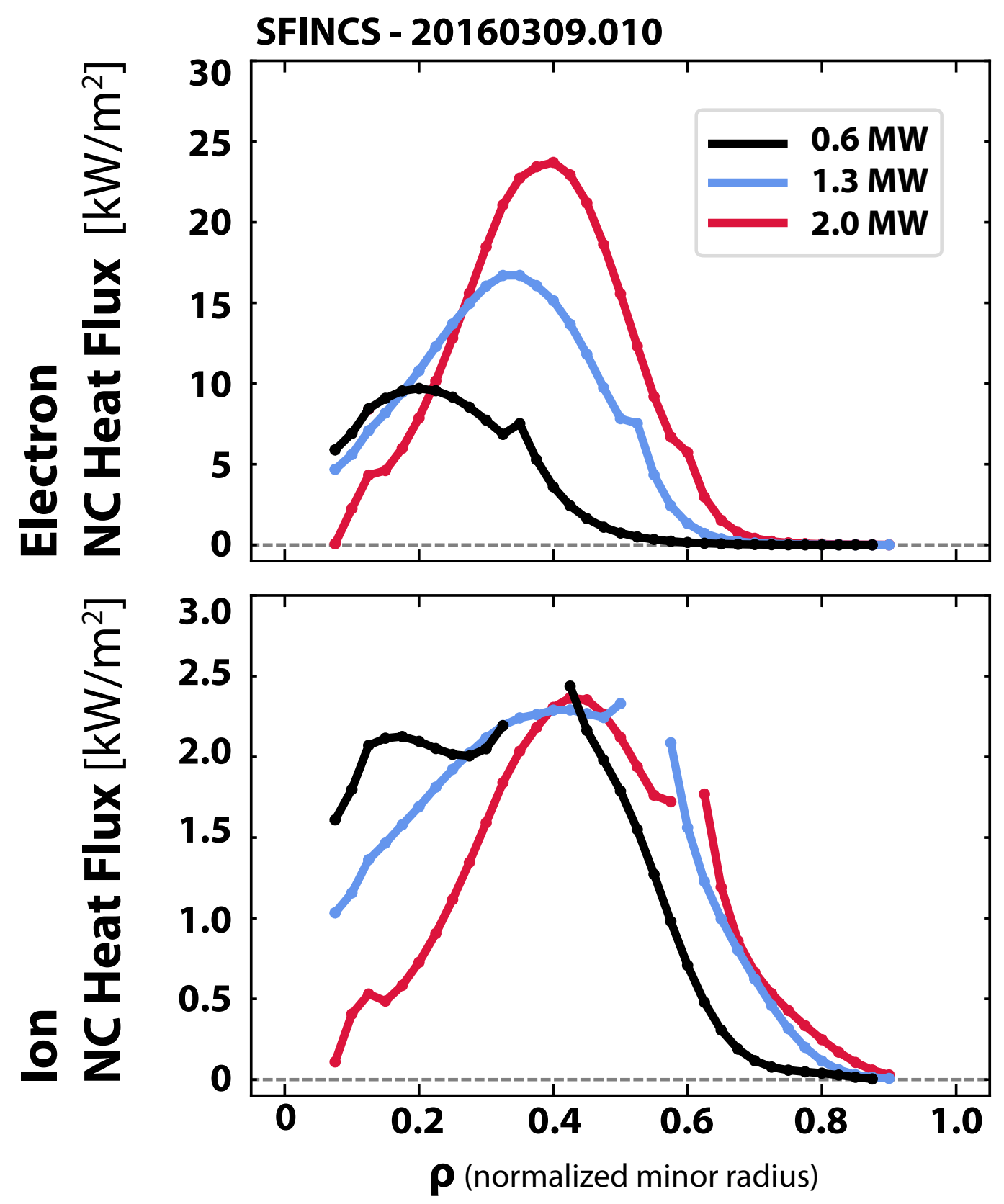

FIG. 6. Comparison of neoclassical heat fluxs as predicted by SFIncs for shot 20160309.010 at the three different power steps. The electrons carry the majority of the neoclassical heat flux which is sensitive to the heating power; the ions, which are not directly heated, have neoclassical heat fluxes that are insensitive to the input ECRH power. Non-physical ion-root solutions around $E_{r}=0$ have been removed from this plot for clarity.

Assuming that the neoclassical electron heat flux can be described as a diffusive processes, $Q_{e}=-n \chi_{e} \frac{\partial T_{e}}{\partial r}$, where $\chi_{e}$ is the effective neoclassical diffusivity, the observed increase in heat flux is only partially explained by the increase in the gradient of $T_{e}$ and indicates 


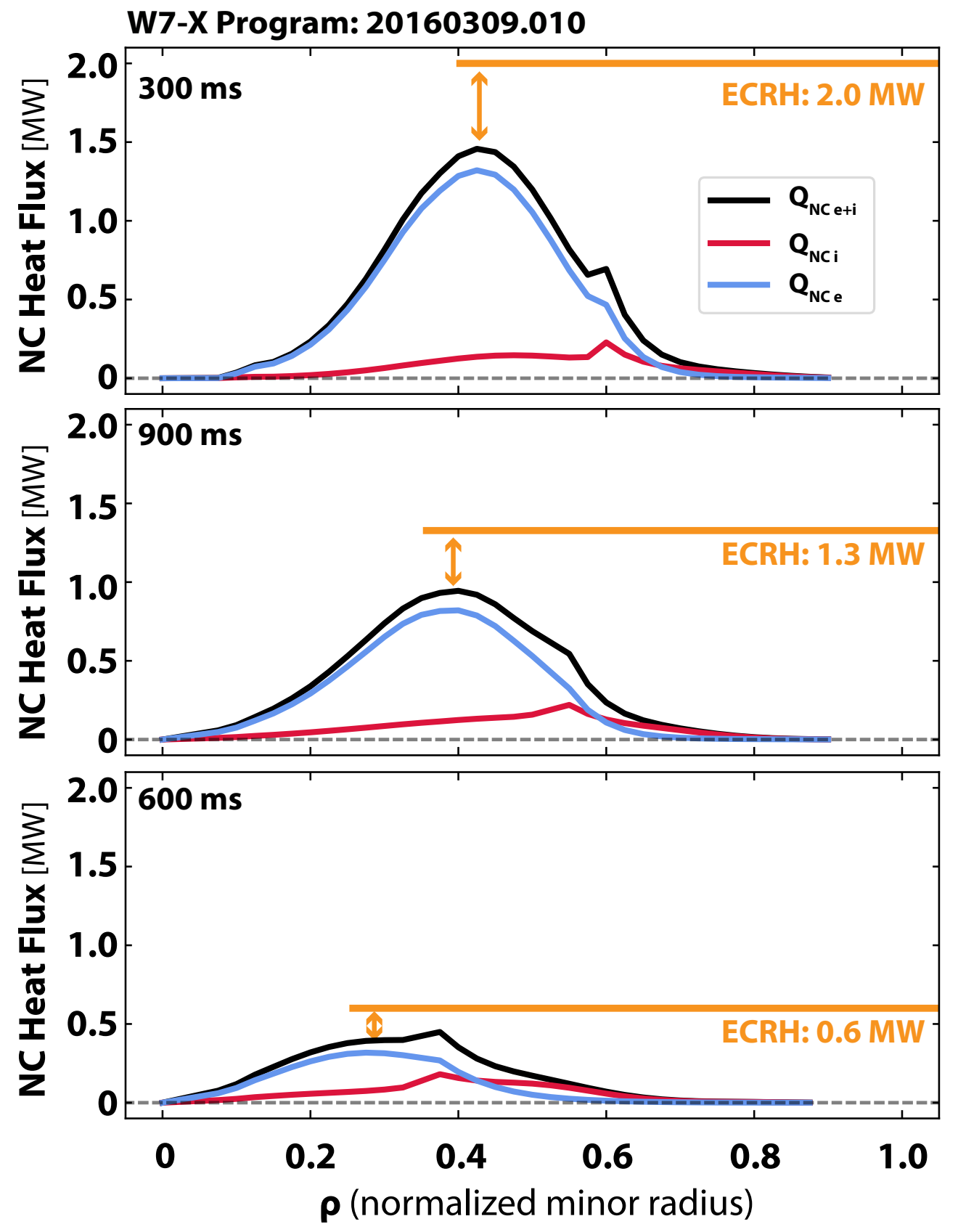

FIG. 7. The total neoclassical heat flux through a given flux surface, as calculated by SFINCS, is shown for each of the three power steps. The total deposited ECRH power is shown by the yellow bar, and is compared to the maximum neocassical transport. In the core, neoclassical heat transport accounts for about $70 \%$ of the total input power for all three power steps.

in increase of the effective neoclassical diffusivity with input power. Possible mechanisms to explain the remainder of the heat flux are turbulent transport, impurity radiation and neutral penetration with subsequent charge exchange. 
In the outer part of the plasma, where turbulence, radiation and charge exchange losses are expected to dominate, the neoclassical heat flux is small compared to the input power ${ }^{12,20}$. This is a general trend of stellarator transport and qualitatively similar to what is seen on W7-AS ${ }^{25}$ and LHD $^{8}$. Measurements of the total radiative power from the bolometer ${ }^{26,27}$ during the three power phases are $0.3 \mathrm{MW}, 0.4 \mathrm{MW}$ and $0.5 \mathrm{MW}$, corresponding to $45 \%$, $30 \%$ and $20 \%$ of the total input power. Further investigation of possible energy transport and loss mechanisms, including turbulence simulations, localization of the radiative power and charge exchange losses and the development of power balance based transport calculations are underway.

\section{CONCLUSION}

First experimental profiles of the radial electric field have been inferred through measurements of the perpendicular plasma flow by the XICS diagnostic. The diagnostic geometry and the expectation of a small parallel velocity allow $E_{r}$ to be inferred by only considering $u_{\perp}$. These measurements show a strong positive-radial electric field in the core of the centrally heated ECRH profiles accessible in the limiter configuration of the first W7-X experimental campaign. Investigation of the evolution of $E_{r}$ during changes in the injected ECRH power show that the radial electric field changes in step with the electron temperature evolution, with a transition time of around $100 \mathrm{~ms}$.

The profiles and dynamic behavior of the radial electric field seen during this experiment are similar to what has been seen previously in CERC plasmas on many stellarator devices such as LHD ${ }^{8}$, W7-AS ${ }^{28}$, TJ-II' ${ }^{29}$, HSX $^{30}$, CHS $^{31}$ and Heliotron-J ${ }^{32}$ (see Ref. 17). In particular the behavior of the radial electric field in response to different levels of central ECRH power is very similar to what has been previously observed in $\mathrm{LHD}^{8}$. At lower input powers only the very central portion of the plasma is seen to have a positive radial electric field, while at higher input powers (and therefore higher central electron temperatures) the region of the plasma in the electron-root expands to cover a majority of the minor radius.

Finally comparisons of the measured radial electric field profiles to neoclassical calculations from three different codes (DKES, SFINCS and FORTEC-3D) show good agreement. This validation has allowed some initial investigation of the role of core neoclassical heat transport in electron-root W7-X discharges. The general agreement between the measured 
and predicted $E_{r}$ profiles provides confidence in the validity of the neoclassical predictions for W7-X and their applicability for both experimental calculation of neoclassical quantities and their use in predictions for future machine performance. More importantly the good agreement between the $E_{r}$ measurements and all three neoclassical calculations suggests that the assumptions that were used in the evaluation of neoclassical transport in the W7X design (which utilized the DKEs code) were appropriate, and likely captured the general neoclassical behavior of the final device.

Research supported by the U.S. DOE under Contract No. DE-AC02-09CH11466 with Princeton University. This work has been carried out within the framework of the EUROfusion Consortium and has received funding from the Euratom research and training programme 2014-2018 under grant agreement No 633053. The views and opinions expressed herein do not necessarily reflect those of the European Commission. Work involving SFINCS is supported by the U.S. DOE under Award Number DE-FG02-93ER5419\%. Simulations utilizing FORTEC-3D have been carried out on Plasma Simulator in NIFS under the support by NIFS collaborative Research Programs NIFS13KNST051.

\section{REFERENCES}

${ }^{1}$ H. Maaßberg, C. D. Beidler, and Y. Turkin, Physics of Plasmas 16, 072504 (2009), http://dx.doi.org/10.1063/1.3175328.

${ }^{2}$ J. Nührenberg and R. Zille, Physics Letters A 114, 129 (1986).

${ }^{3}$ C. Beidler, G. Grieger, F. Herrnegger, E. Harmeyer, J. Kisslinger, W. Lotz, H. Maassberg, P. Merkel, J. Nührenberg, F. Rau, J. Sapper, F. Sardei, R. Scardovelli, A. Schlüter, and H. Wobig, Fusion Technology 17, 148 (1990), http://www.tandfonline.com/doi/pdf/10.13182/FST90-A29178.

${ }^{4}$ H. Maassberg, W. Lotz, and J. Nührenberg, Physics of Fluids B: Plasma Physics 5, 3728 (1993), http://dx.doi.org/10.1063/1.860843.

${ }^{5}$ Y. Turkin, C. D. Beidler, H. Maaßberg, S. Murakami, V. Tribaldos, and A. Wakasa, Physics of Plasmas 18, 022505 (2011), http://dx.doi.org/10.1063/1.3553025.

${ }^{6}$ W. I. van Rij and S. P. Hirshman, Physics of Fluids B 1, 563 (1989).

${ }^{7}$ N. Pablant, M. Bitter, R. Burhenn, L. Delgado-Aparicio, R. Ellis, D. Gates, M. Goto, K. Hill, A. Langenberg, S. Lazerson, M. Mardenfeld, S. Morita, G. H. Neilson, T. Oishi, and T. Pedersen, 41st EPS Conference on Plasma Phyisics, Europhysics Conference Abstracts 38F, P1.076 (2014).

${ }^{8}$ N. A. Pablant, S. Satake, M. Yokoyama, D. A. Gates, M. Bitter, N. Bertelli, L. DelgadoAparicio, A. Dinklage, M. Goto, K. W. Hill, S. Igamai, S. Kubo, S. Lazerson, S. Matsuoka, 
D. R. Mikkelsen, S. Morita, T. Oishi, R. Seki, T. Shimozuma, C. Suzuki, Y. Suzuki, H. Takahashi, H. Yamada, Y. Yoshimura, and the LHD Experiment Group, Plasma Physics and Controlled Fusion 58, 045004 (2016).

${ }^{9}$ N. A. Pablant, R. E. Bell, M. Bitter, L. Delgado-Aparicio, K. W. Hill, S. Lazerson, and S. Morita, Review of Scientific Instruments 85, 11E424 (2014).

${ }^{10}$ M. Bitter, K. Hill, D. Gates, D. Monticello, H. Neilson, A. Reiman, A. L. Roquemore, S. Morita, M. Goto, H. Yamada, and J. E. Rice, Review of Scientific Instruments 81, 10E328 (2010).

${ }^{11}$ J. Arévalo, J. Alonso, K. McCarthy, and J. Velasco, Nuclear Fusion 53, 023003 (2013).

${ }^{12}$ M. Hirsch, A. Dinklage, A. Alonso, G. Fuchert, S. Bozhenkov, U. Höfel, T. Andreeva, J. Baldzuhn, M. Beurskens, H.-S. Bosch, C. Beidler, C. Biedermann, E. Blanco, R. Brakel, R. Burhenn, B. Buttenschön, A. Cappa, A. Czarnecka, M. Endler, T. Estrada, T. Fornal, J. Geiger, O. Grulke, J. Harris, D. Hartmann, M. Jakubowski, T. Klinger, J. Knauer, G. Kocsis, R. König, P. Kornejew, A. Krämer-Flecken, N. Krawczyk, M. Krychowiak, M. Kubkowska, I. Ksiazek, A. Langenberg, H. Laqua, S. Lazerson, H. Maaßberg, N. Marushchenko, S. Marsen, V. Moncada, D. Moseev, D. Naujoks, M. Otte, N. Pablant, E. Pasch, F. Pisano, K. Rahbarnia, T. Schröder, T. Stange, L. Stephey, T. Szepesi, T. S. Pedersen, H. T. Mora, H. Thomsen, H. Tsuchiya, Y. Turkin, T. Wauters, G. Weir, U. Wenzel, A. Werner, R. Wolf, G. Wurden, D. Zhang, and the W7-X Team, Nuclear Fusion 57, 086010 (2017).

${ }^{13}$ T. Windisch, A. Kraemer-Flecken, J. Velasco, A. Koenies, C. Nuehrenberg, O. Grulke, and T. Klinger, Plasma Physics and Controlled Fusion (2017), 10.1088/1361-6587/aa759b.

${ }^{14}$ A. Krämer-Flecken, T. Windisch, W. Behr, G. Czymek, P. Drews, G. Fuchert, J. Geiger, O. Grulke, M. Hirsch, M. Knaup, Y. Liang, O. Neubauer, E. Pasch, J. Velasco, and T. W.-X. Team, Nuclear Fusion 57, 066023 (2017).

${ }^{15}$ M. Hirsch, A. Benndorf, E. Blanco, R. Burhenn, A. Cappa, T. Estrada, K. Ewert, G. Gliege, H.-J. Hartfuss, C. Heuer, R. Herrmann, W. Kasparek, J. P. Knauer, P. Kornejew, A. Krämer-Flecken, F. Lapayese, B. van Milligen, S. Mohr, U. Neuner, L. Pacios, A. de la Peña 2, D. Pilopp, B. Plaum, N. Rüter, T. Sieber, T. Stange, M. Steffen, T. SunnPedersen, H. Trimino-Mora, D. Wagner, T. Windisch, and S. Wolf, Proceedings of Science ECPD2015, 111 (2015).

${ }^{16}$ T. S. Pedersen, A. Dinklage, Y. Turkin, R. Wolf, S. Bozhenkov, J. Geiger, G. Fuchert, 
H.-S. Bosch, K. Rahbarnia, H. Thomsen, U. Neuner, T. Klinger, A. Langenberg, H. T. Mora, P. Kornejew, J. Knauer, M. Hirsch, and N. Pablant, Physics of Plasmas 24, 055503 (2017), http://dx.doi.org/10.1063/1.4983629.

${ }^{17}$ M. Yokoyama, H. Maaßberg, C. Beidler, V. Tribaldos, K. Ida, T. Estrada, F. Castejon, A. Fujisawa, T. Minami, T. Shimozuma, Y. Takeiri, A. Dinklage, S. Murakami, and H. Yamada, Nuclear Fusion 47, 1213 (2007).

${ }^{18}$ T. Klinger, A. Alonso, S. Bozhenkov, R. Burhenn, A. Dinklage, G. Fuchert, J. Geiger, O. Grulke, A. Langenberg, M. Hirsch, G. Kocsis, J. Knauer, A. Krämer-Flecken, H. Laqua, S. Lazerson, M. Landreman, H. Maaßberg, S. Marsen, M. Otte, N. Pablant, E. Pasch, K. Rahbarnia, T. Stange, T. Szepesi, H. Thomsen, P. Traverso, J. L. Velasco, T. Wauters, G. Weir, T. Windisch, and T. W. .-X. Team, Plasma Physics and Controlled Fusion 59, 014018 (2017).

${ }^{19}$ A. Dinklage, A. Alonso, J. Baldzuhn, C. Beidler, C. Biedermann, B. Blackwell, S. Bozhenkov, R. Brakel, B. Buttenschön, Y. Feng, G. Fuchert, J. Geiger, M. Hirsch, U. Hoefel, J. Knauer, A. Krämer-Flecken, A. Langenberg, H. Laqua, H. Maaßberg, N. Pablant, E. Pasch, K. Rahbarnia, T. Stange, L. Stephey, H. Trimino-Mora, Y. Turkin, J.-L. Velasco, G. Wurden, D. Zhang, T. Andreeva, M. Beurskens, E. Blanco, H.-S. Bosch, R. Burhenn, A. Cappa, A. Czarnetzka, M. Endler, T. Estrada, T. Fornal, O. Grulke, D. Hartmann, J. Harris, P. Helander, M. Jakubowski, T. Klinger, S. Klose, G. Kocsis1, R. König, P. Kornejew, N. Krawczyk, M. Krychowiak, M. Kubkowska, I. Kiazek, H. Laqua, M. Landreman, S. Lazerson, S. Marsen, N. Marushchenko, V. Moncada, D. Moseev, D. Naujoks, M. Otte, T. Pedersen, F. Pisano, K. Riße, T. Rummel, O. Schmitz, S. Satake, T. Schröder, T. Szepesi1, H. Thomsen, P. Traverso, M. Tsuchiya, T. Wauters, G. Weir, R. Wolf, M. Yokoyama16, and the W7-X Team, 43rd EPS Conference on Plasma Physics , O2.107 (2016).

${ }^{20}$ R. C. Wolf, C. Beidler, M. Beurskens, C. Biedermann, H.-S. Bosch, S. Bozhenkov, R. Brakel, A. Dinklage, Y. Feng, G. Fuchert, O. Grulke, M. Hirsch, U. Höfel, M. Jakubowski, J. Knauer, G. Kocsis, R. König, P. Kornejew, A. Kraemer-Flecken, A. Langenberg, H. Laqua, S. Lazerson, S. Marsen, N. Marushchenko, D. Moseev, N. Pablant, E. Pasch, K. Rahbarnia, T. Stange, T. S. Pedersen, J. Svensson, T. Szepesi, H. TriminoMora, Y. Turkin, T. Wauters, G. Wurden, and D. Zhang, Nuclear Fusion (2017), 10.1088/1741-4326/aa770d. 
${ }^{21}$ M. Landreman, H. M. Smith, A. Mollén, and P. Helander, Physics of Plasmas 21, 042503 (2014), http://dx.doi.org/10.1063/1.4870077.

${ }^{22}$ S. Satake, M. Okamoto, N. Nakajima, H. Sugama, M. Yokoyama, and C. Beidler, Nuclear Fusion 45, 1362 (2005).

${ }^{23}$ S. Matsuoka, S. Satake, M. Yokoyama, A. Wakasa, and S. Murakami, Physics of Plasmas 18, 032511 (2011).

${ }^{24}$ E. Pasch, M. Beurskens, S. Bozhenkov, G. Fuchert, M. Hirsch, U. Hoefel, J. Knaue, P. Kornejew, A.Langenberg, N. Pablant, R. Wolf, and the W7-X Team, 43rd EPS Conference on Plasma Physics, P4.016 (2016).

${ }^{25}$ J. Baldzuhn, M. Kick, H. Maassberg, and the W7-AS Team, Plasma Physics and Controlled Fusion 40, 967 (1998).

${ }^{26}$ D. Zhang, R. Burhenn, R. Koenig, L. Giannone, P. A. Grodzki, B. Klein, K. Grosser, J. Baldzuhn, K. Ewert, V. Erckmann, M. Hirsch, H. P. Laqua, and J. W. Oosterbeek, Review of Scientific Instruments 81, 10E134 (2010), https://doi.org/10.1063/1.3483194.

${ }^{27}$ D. Zhang, R. Burhenn, B. Buttenschön, R. König, R. Laube, H. Jenszch, L. Giannone, M. Marquardt, H. Thomsen, A. Werner, A. Alonso, C. Biedermann, S. Bozhenkov, R. Brakel, A. Czarnecka, T. Fornal, G. Fuchert, O. Grulke, M. Hirsch, J. Knauer, M. Kubkowska, A. Langenberg, H. P. Laqua, M. Otte, N. Pablant, E. Pasch, K. Rahbarnia, T. Schröder, J. Svensson, U. Wenzel, G. Wurden, and The W7-X Team, 43rd EPS Conference on Plasma Physics, P4.015 (2016).

${ }^{28}$ M. Romé, C. D. Beidler, H. Maaßberg, N. B. Marushchenko, Y. A. Turkin, and the W7-AS Team, Plasma Physics and Controlled Fusion 48, 353 (2006).

${ }^{29}$ F. Castejón, V. Tribaldos, I. García-Cortés, E. de la Luna, J. Herranz, I. Pastor, T. Estrada, and T.-I. Team, Nuclear Fusion 42, 271 (2002).

${ }^{30}$ J. Lore, W. Guttenfelder, A. Briesemeister, D. T. Anderson, F. S. B. Anderson, C. B. Deng, K. M. Likin, D. A. Spong, J. N. Talmadge, and K. Zhai, Physics of Plasmas 17, 056101 (2010), http://dx.doi.org/10.1063/1.3300465.

${ }^{31}$ T. Minami, N. Kenmochi, C. Takahashi, K.Nishioka, S. Kobayashi, Y. Nakamura, H. Okada, S. Kado, S. Yamamoto, S. Ohshima, S. Konoshima, G. Weir, Y. Ohtani, K. Nagasaki, T. Mizuuchi, and F. Sano, 42rd EPS Conference on Plasma Physics , P5.103 (2015).

${ }^{32}$ N. Kenmochi, T. Minami, C. Takahashi, S. Tei, K. Nishioka, T. Mizuuchi, S. Kobayashi, 
K. Nagasaki, Y. Nakamura, H. Okada, S. Kado, S. Yamamoto, S. Ohshima, S. Konoshima, G. M. Weir, Y. Otani, and F. Sano, 42rd EPS Conference on Plasma Physics, P5.131 (2015). 